\title{
CHOQUE DE GESTÃO OU CHOQUE DE RACIONALIDADES? O DESEMPENHO DA ADMINISTRAÇÃO PÚBLICA EM QUESTÃO
}

\author{
Vanessa Brulon \\ vanessabrulon@gmail.com \\ Fundação Getúlio Vargas - Rio de Janeiro, RJ/Brasil \\ Marcelo Milano Falcão Vieira (in memoriam) \\ Leonardo Darbilly \\ leonardo.darbilly@fgv.br \\ Fundação Getúlio Vargas - Rio de Janeiro, RJ/Brasil
}

\begin{abstract}
Recebido em 29/09/2011
Aprovado em 12/03/2013

Disponibilizado em 01/04/2013

Avaliado pelo sistema double blind review

Revista Eletrônica de Administração

Editor: Luís Felipe Nascimento

ISSN 1413-2311 (versão on-line)

Editada pela Escola de Administração da Universidade Federal do Rio Grande do Sul.

Periodicidade: Quadrimestral

Sistema requerido: Adobe Acrobat Reader.
\end{abstract}

\section{RESUMO}

A partir dos processos de reforma gerencial colocados em prática em âmbito mundial, desencadearam-se propostas de reformas seguindo esta mesma lógica, também em nível estadual. O programa Choque de Gestão, implementado no Estado de Minas Gerais, é um exemplo deste tipo de proposta e merece destaque por ser avaliado de maneira bastante positiva na literatura especializada. Neste sentido, o objetivo do presente trabalho é analisar em que medida o programa Choque de Gestão, do Governo do Estado de Minas Gerais, compreende as diferentes dimensões de desempenho. Para tal, propõe-se um modelo teórico que relacione os conceitos de racionalidade instrumental e racionalidade substantiva, conforme analisadas por Ramos (1989), com o paradigma multidimensional proposto por Sander (1995). Para este último, a noção de desempenho deve ser pensada de forma mais ampla, tendo como base os critérios de eficiência, eficácia, efetividade e relevância. Aos conceitos de eficiência e eficácia relaciona-se o de racionalidade instrumental, baseada no cálculo utilitário das consequiências, e aos de efetividade e relevância, o de racionalidade substantiva, fundamentada em valores. A relação entre os conceitos representa o quadro referencial de análise da pesquisa. Optou-se pela pesquisa qualitativa e os dados foram coletados por meio de pesquisa documental e analisados por meio do método de análise argumentativa. Para a realização da análise, foram utilizadas as categorias de substantividade e instrumentalidade, e foram criados indicadores, com base no referencial teórico, de acordo com as categorias trabalhadas. Por meio destes indicadores, analisou-se o documento Plano Mineiro de Desenvolvimento Integrado (PMDI), que consiste no planejamento de longo prazo do programa Choque de Gestão. A partir da análise realizada, pode-se observar que o conceito de desenvolvimento orientador do PMDI está impregnado de elementos substantivos, como a

REAd I Porto Alegre - Edição 74 - N 1 - jan/abr 2013 - p. 1-34 
Choque de gestão ou choque de racionalidades? O desempenho da administração pública em questão

preocupação com a qualidade de vida ou com o atendimento das demandas sociais e, por isso, guia-se por uma visão de futuro que representa um Estado em que estão presentes as duas categorias aqui trabalhadas. Entretanto, o conceito de desempenho em que está pautado, engloba aspectos predominantemente instrumentais, já que se acredita que para que a administração pública mineira melhore seu desempenho basta que ela adote medidas como a redução de custos ou o foco em resultados. Portanto, conclui-se que o conceito de desempenho em que se pauta o programa Choque de Gestão não compreende as diferentes dimensões de desempenho de forma equilibrada, apesar de se guiar por um conceito de desenvolvimento que envolve elementos substantivos e instrumentais.

Palavras-chave: Administração pública; desempenho; racionalidade; programa Choque de Gestão.

\title{
MANAGEMENT SHOCK OR RATIONALITY SHOCK? THE PERFORMANCE OF PUBLIC ADMINISTRATION PUT INTO QUESTION
}

\begin{abstract}
Since the management reform process spread worldwide, other reform proposals following the same logic were put into practice, most of them at the state level. The Management Shock program, implemented in the State of Minas Gerais, Brazil, is one example of such a proposal and deserves to be highlighted due to the very positively evaluations it received in specialized literature. Therefore, the objective of this study is to analyze to what extent the program Management Shock, implemented by the Government of Minas Gerais, incorporates the different dimensions inherent to the concept of performance. For the analysis of this program, we propose a theoretical model that relates the concepts of instrumental rationality and substantive rationality, as analyzed by Ramos (1989), with the multidimensional paradigm, proposed by Sander (1995). For the latter, the notion of performance should be broadened, incorporating the criteria of efficiency, effectiveness, responsiveness and relevance. The concepts of efficiency and effectiveness are related to instrumental rationality or the utilitarian calculation of consequences; while effectiveness and relevance are related to substantive rationality, based on values. The relationship between the six concepts represents the theoretical framework adopted for data analysis. Data were collected through documentary research and analyzed through the qualitative method of argumentative analysis. For the analysis, the categories of substantivity and instrumentality were used, and indicators were created based on the theoretical framework. Through these indicators, the document entitled Integrated Development Plan of Minas Gerais (PMDI), which consists of long-term planning of the program Management Shock, was analyzed. From the analysis, it can be observed that the guiding concept of development is impregnated with PMDI substantive elements, such as concerns about the quality of life and about meeting social needs. However, the concept of performance in which it is based includes aspects predominantly instrumental, since it is believed that in order for government to improve its performance it is enough to reduce costs or focus on results. Therefore, we conclude that the concept of performance in which the Shock Management program is guided does not include the different dimensions of
\end{abstract}

REAd I Porto Alegre - Edição 74 - N 1 - jan/abr 2013 - p. 1-34 
Vanessa Brulon, Marcelo Milano Falcão Vieira (in memoriam) \& Leonardo Darbilly

performance in a balanced way, while being guided by a development concept that involves substantive and instrumental elements.

Keywords: Public administration; performance; rationality; Management Shock Program.

\section{INTRODUÇÃO}

A partir da década de 1970, teve início nos EUA e na Inglaterra uma tendência a transferir práticas gerenciais do setor privado para a administração pública, fornecendo as bases para o modelo gerencial de administração, que também ficou conhecido como Nova Administração Pública. Tal modelo fortaleceu-se na década de 1980, sendo adotado por governos de muitos países, com o objetivo de aumentar a eficiência do Estado. Seguindo os pressupostos neoliberais, a Nova Administração Pública propõe a transferência e adaptação de idéias, valores e práticas do setor privado para o setor público (PAULA, 2005).

Os processos de reforma de Estado, que ocorreram nos EUA e no Reino Unido na década de 1980, marcaram o início da tendência mundial ao desenvolvimento de reformas gerenciais no setor público. As transformações colocadas em prática durante o Governo de Margaret Tatcher, no Reino Unido, e durante o Governo Reagan, nos EUA, são tidas como uns dos principais exemplos de implementação de reforma gerencial aplicada ao setor público.

No Brasil, a reforma gerencial teve início durante o Governo do presidente Fernando Henrique Cardoso, na década de 1990, com a criação do Ministério da Administração Federal e Reforma do Estado (MARE) e sob o comando do então ministro Luiz Carlos BresserPereira. Segundo Bresser-Pereira (2006), a reorganização do setor público se deu em resposta à crise vivida pelo País durante a década de 1980. O autor explica que a reforma teve como objetivos facilitar o ajuste fiscal, tornar a administração pública mais moderna e eficiente e voltar-se para o atendimento dos cidadãos.

Neste sentido, a Nova Administração Pública ganha destaque por estar associada à idéia de eficiência, sendo a redução de custos um de seus principais objetivos. Porém, o referido modelo também é alvo de fortes críticas. Dentre elas, pode-se citar a inadequação das práticas de empresas privadas para o setor público, a tendência a privatizações, a dicotomização entre administração e política ou o afastamento da administração pública de sua função social (PAULA, 2005; PETERS, 1991).

Não obstante as críticas, no início do século XXI, a tendência à perpetuação dos pressupostos da Nova Administração Pública parece perdurar. Muitos projetos de reforma da 
Choque de gestão ou choque de racionalidades? O desempenho da administração pública em questão

administração pública continuam a ser colocados em prática com vistas a aproximá-la do modelo privado de administração, tendo como fundamento as teorias organizacionais dominantes na lógica empresarial. No Brasil, merece destaque o processo de reforma denominado como Choque de Gestão, posto em prática no Estado de Minas Gerais, durante o Governo de Aécio Neves, a partir de 2003. Tal programa serve como exemplo do predomínio do pensamento gerencialista na administração pública brasileira atual.

Visando a modernizar o aparato estatal de Minas Gerais e a superar o modelo burocrático de administração, o programa Choque de Gestão foi implementado em 2003, diante da necessidade de corrigir a situação deficitária do Estado. Tal reforma buscou maior eficiência do Estado, através do foco em resultados, seguindo os princípios do modelo gerencial. A partir desta proposta, procurou-se alcançar uma administração pública empreendedora, que busca implementar novos modelos de gestão e desenvolvimento de políticas públicas voltados para a inovação e a modernização da administração pública.

Evidenciando a tendência de disseminação da Nova Administração Pública, o programa Choque de Gestão foi levado para outros estados do Brasil, como São Paulo e Rio de Janeiro. Ao se observar a difusão de reformas como esta, tornam-se claros tanto a legitimação de tais políticas na esfera da gestão pública quanto o alcance restrito das críticas que têm sido feitas a esses modelos.

Diante das mudanças pelas quais a administração pública vem passando, especialmente no contexto do inicio do século XXI, importa ainda discutir se é este o modelo que melhor contribui para seu bom desempenho, tendo em vista a sua função social. Guerreiro Ramos (1989, VII), para dar início às suas reflexões em A nova ciência das organizações: uma reconceituação da riqueza das nações, expressa inconformidade com o cenário de sua época a partir da citação de um fragmento de Kant na Crítica da razão pura: "Nada é mais censurável do que deduzir as leis que determinam aquilo que deveria ser feito daquilo que é feito, ou impor a tais leis os limites a que se circunscreve aquilo que é feito". Indo ao encontro de Guerreiro Ramos (1989), ainda que tais modelos já estejam consumados e representem a forma como as coisas se dão na administração pública atual, é de extrema relevância refletir sobre sua adequabilidade.

Em 1970, Guerreiro Ramos (1970) já chamava atenção para a necessidade de que os pressupostos da administração pública fossem repensados. Como um instrumento colocado a serviço do Estado e, por essa razão, responsável pelo alcance do bem comum, a administração pública possui uma função social a cumprir. Entretanto, quando ela o faz com o predomínio 
Vanessa Brulon, Marcelo Milano Falcão Vieira (in memoriam) \& Leonardo Darbilly

da lógica instrumental, tal função acaba não se concretizando, uma vez que preocupações com redução de gastos e alcance de resultados podem acabar tornando-se fins em si mesmo, em detrimento de objetivos de cunho social. Por meio do predomínio da substantividade, por outro lado, introduzem-se padrões éticos na administração pública e esta passa a orientar-se com base em um postulado de valores na busca de objetivos coletivos, tal como mostrou Kalberg (1980).

Ao se constituir como um pilar fundamental do Estado, a administração pública precisa apresentar um bom desempenho no cumprimento de suas funções. Diante da importância de aspectos substantivos no alcance do bem comum, argumenta-se que um modelo multidimensional para análise do desempenho da administração pública seria o mais adequado, uma vez que compreende critérios tanto substantivos como instrumentais. Sander (1995) apresenta um modelo que se constitui em um esforço de compreender os principais critérios de desempenho que orientam a ação administrativa, incluindo, além dos critérios tradicionais de natureza econômica, como os de eficiência e eficácia, critérios de natureza política e cultural, como os de efetividade e relevância. Desta forma, a noção de desempenho relativa ao modelo assume um caráter mais amplo, adequando-se melhor à administração pública, na qual critérios substantivos assumem papel central.

Há, entretanto, uma tendência a avaliar o desempenho por meio do privilégio de critérios instrumentais, como a eficiência e a eficácia, assumindo-se uma visão restrita e limitada do conceito. Tal tendência é reforçada diante do predomínio da lógica instrumental em todas as esferas da vida humana, característica da sociedade centrada no mercado ${ }^{1}$, como mostrou Guerreiro Ramos (1989).

No início do século XXI esta discussão se faz ainda mais urgente. Em um contexto em que as discussões em torno da noção de desempenho na administração pública se voltam quase que exclusivamente para o critério de eficiência, faz-se necessário colocá-la em questão, tendo em vista a sua ampliação. Ainda, tomando o programa Choque de Gestão como objeto de análise, pretende-se trazer reflexões sobre um programa de reforma recente, que merece ser mais discutido, já que recebeu grande aceitação e se disseminou para outros estados do País. É nesse sentido que o presente trabalho possui como objetivo analisar em que medida o programa Choque de Gestão, do Governo do Estado de Minas Gerais, compreende as diferentes dimensões de desempenho. 
Choque de gestão ou choque de racionalidades? O desempenho da administração pública em questão

\section{FUNDAMENTAÇÃO TEÓRICA}

\subsection{Em busca do bem comum: a administração pública como instrumento do Estado}

O caráter social da administração pública está presente em suas principais definições, apesar de se tratar de um conceito amplo e complexo, não existindo uma definição clara do termo, como mostrou Matias-Pereira (2009). Ainda assim, em uma tentativa de conceituá-la, o autor define a administração pública como "o conjunto de serviços e entidades incumbidos de concretizar as atividades administrativas, ou seja, da execução das decisões políticas e legislativas" (MATIAS-PEREIRA, 2009, p. 62). Nesse sentido, Matias-Pereira (2009) defende que o propósito da administração pública é a gestão de bens e interesses da comunidade nos três níveis de governo - municipal, estadual e federal - para o alcance do bem comum.

A administração pública é, assim, diferente do Estado, mas está a ele diretamente ligada. A este respeito, Matias-Pereira (2009, p. 129) explica que o Estado é "um conjunto de instituições criadas, recriadas e ajustadas para administrar conflitos e tensões em um determinado território, ou seja, a noção de conflito e tensão é essencial a esse conceito". A partir desta definição, o autor defende que o Estado se materializa por meio da administração pública, bem como de instituições, como o Executivo, o Legislativo e o Judiciário, das forças militares, e dos governos subnacionais. Desta forma, a administração pública, assim como as demais instituições citadas, vai "materializar e arbitrar esses conflitos e tensões que são levados para o Estado" (MATIAS-PEREIRA, 2009, p. 129). Gaitan (1989) complementa esta idéia ao afirmar que a administração pública cumpre os fins definidos pelo Estado, constituindo-se como seu pilar fundamental. Na visão do autor, a administração pública é responsável pela execução das decisões do Estado, atuando como "um instrumento que o estado mobiliza para a execução prática de seus programas" (GAITAN, 1989, p. 49). Neste sentido, Gaitan (1989) destaca como finalidade da administração pública a realização de ações que possibilitem o alcance dos objetivos do Estado. Para o autor, os fins da administração pública estão diretamente relacionados com os fins do Estado.

A administração pública é caracterizada, assim, por atuar como representante do Estado na busca do bem comum, tido como seu objetivo primeiro. Esta idéia ganha destaque com o pensamento de Rousseau ${ }^{2}$ (2006), que traz à tona a discussão a respeito da função social do Estado, ao defender que cada membro de uma comunidade a ela se entrega no 
Vanessa Brulon, Marcelo Milano Falcão Vieira (in memoriam) \& Leonardo Darbilly

momento de sua formação, estabelecendo um contrato social, a partir do qual é formada a sociedade e, então, o Estado. Para o autor, a ordem social é um direito de todos, mas se constitui como um direito que advém de convenções, que levam à formação do Estado. $\mathrm{O}$ contrato social explicitado por Rousseau (2006) permite que todos se associem para que se mantenham protegidos e protejam seus bens, continuando, ainda assim, livres. Desta forma, por meio do contrato social, cada indivíduo deixa-se guiar pela vontade geral, formando uma pessoa pública que o autor identifica como "república” ou "corpo político".

Caldera e Telo (1976) defendem que não se pode negar o fato de que, quando se vive em sociedade, esta se torna responsável por fornecer as condições necessárias para que cada um seja capaz de obter a satisfação de suas necessidades. Matias-Pereira (2009) reforça esta idéia ao afirmar que a principal função do Estado é realizar o bem-comum, que pode ser desdobrado em três vertentes principais: o bem-estar, a segurança e a justiça. Nesse sentido, para o autor, o Estado deve sempre agir de acordo com o interesse coletivo, sendo a base de seu dever político um dever moral. Douglass (1980) complementa esta idéia ao afirmar que o bem comum, em sua formulação tradicional, era tido como uma idéia política, sendo considerado como o principal objetivo do Estado. Segundo o autor, o Estado, nesta concepção tradicional, não teria nenhum outro propósito a não ser servir ao bem comum. Para Caldera e Telo (1976), a função do Estado de alcançar o bem comum não deve estar limitada apenas a circunstâncias econômicas, mas também aos campos cultural e moral.

Pode-se observar, assim, o destaque dado ao bem comum como o principal objetivo do Estado, idéia que se mostra presente desde o século XVIII com Rousseau. Diante da importância deste conceito quando se discute administração pública, muitos autores destinaram seus esforços a tentar defini-lo. Advindo da filosofia cristã, o conceito de bem comum é muitas vezes intercambiado com outros conceitos, tais como bem público, bem social, bem coletivo, bem-estar comum, ou interesse geral, como mostraram Caldera e Tello (1976). Diante da enorme variedade de conceitos que se confundem, a definição de bem comum ainda continua sendo marcada por uma falta de consenso. O'Connor (2002) explica que o conceito de bem comum surge como uma norma moral para determinar as políticas nacionais e o efeito da globalização na vida das pessoas. Marcum (2001, p. 73), por exemplo, defende que o bem comum "é o bem estar de uma comunidade considerada como um todo". Indo ao encontro de Marcum (2001), London (2003), ao diferenciar o bem comum do interesse individual, o define como um conjunto de interesses que é fundamental e básico para os indivíduos e que é comum a cada um dos membros da comunidade. Partindo da definição 
Choque de gestão ou choque de racionalidades? O desempenho da administração pública em questão

clássica do termo, derivada dos princípios aristotélicos, Dupré (1993) considera o bem comum como um bem próprio para a comunidade, apesar de ser individualmente compartilhado pelos membros. Para Maritain e FitzGerald (1946), o bem comum não é nem o conjunto de bens privados, nem o bem de um todo, mas sim a comunhão de pessoas em um

bem viver. É comum para o todo e para as partes, simultaneamente. É um bem que segue os requisitos de justiça, e que inclui como valor principal o acesso à liberdade. Os autores acrescentam, ainda, que o bem comum apenas se constitui como tal se for redistribuído entre as pessoas. Indo ao encontro de Maritain e FitzGerald (1946), Douglass (1980) afirma que o bem comum consiste em vários objetivos específicos que servem para promover o bem-estar humano, defendendo também que ele é mais do que a soma de bens individuais.

Com o importante papel de levar ao bem comum, o Estado tem na administração pública seu principal instrumento para alcançá-lo. Para cumprir da melhor forma possível a sua função social, a administração pública precisa colocar no centro de suas ações critérios que tenham como finalidade última a preocupação com o bem estar da coletividade. Dessa forma, um modelo multidimensional, capaz de proporcionar a avaliação dos resultados da administração pública tanto em aspectos substantivos, ligados diretamente ao bem comum, como aspectos instrumentais, necessários ao bom uso dos recursos e dos meios para se chegar aos fins, parece adequar-se à natureza também multidimensional do objeto que se propõe analisar.

\subsection{Racionalidade e desempenho: por um paradigma multidimensional}

O conceito de razão é central em qualquer ciência. A razão prescreve como os seres agem e ordenam a sociedade, permitindo a distinção entre o certo e o errado, o bem e o mal, e a separação entre o conhecimento falso e o verdadeiro (GUERREIRO RAMOS, 1989). Barros e Passos (2000) a destacam como o critério de distinção entre os seres humanos e os demais seres da natureza.

Ao longo de sua evolução, a idéia de racionalidade foi levada a uma dicotomização entre as dimensões de instrumentalidade e substantividade (BARROS e PASSOS, 2000). A multiplicidade da noção de racionalidade pode ser observada na obra de Weber, que reforça a discussão a respeito da razão de forma rigorosa e consistente, na visão de Eisen (1978). Kalberg (1980), ao analisar a obra de Weber, dela destaca quatro tipos de racionalidade: a racionalidade prática, que se baseia em interesses puramente pragmáticos e egoístas; a racionalidade teórica, que envolve um domínio consciente da realidade através da construção 
Vanessa Brulon, Marcelo Milano Falcão Vieira (in memoriam) \& Leonardo Darbilly

de conceitos abstratos precisos; a racionalidade substantiva, que se baseia em um postulado de valor; e a racionalidade formal, que se baseia em cálculos racionais meio-fins, que fazem referência a leis universais. A partir da obra de Weber, assim, muitos autores que se sucederam passaram a analisar a realidade por meio da lógica da racionalidade, dando atenção especial à tensão existente entre as duas últimas.

Merece destaque, neste sentido, a obra de Guerreiro Ramos A nova ciência das organizações: uma reconceituação das riquezas das nações, na qual o autor demonstra a centralidade do conceito de razão, e faz uma crítica contundente à razão moderna, caracterizada como razão instrumental. Para Guerreiro Ramos (1989), o conceito de razão está deturpado, sendo identificado apenas à racionalidade instrumental. É neste sentido que o autor apresenta a distinção, estabelecida por Weber, entre racionalidade instrumental e racionalidade substantiva, criticando o predomínio da primeira, em defesa da retomada da última.

O predomínio da racionalidade instrumental em todas as esferas da vida humana, denunciado por Guerreiro Ramos (1989), também se reflete na administração pública. As discussões em torno dos critérios de desempenho nos quais a administração pública deve se pautar espelha a tensão entre instrumentalidade e substantividade apontada na literatura que discute o conceito de razão. É corrente nos debates a respeito da mensuração de desempenho no setor público, a defesa dos critérios de eficiência, entendido como a redução dos recursos necessários, ou de eficácia, assumido como o alcance dos objetivos propostos, como aqueles mais relevantes (HATRY, 1999; ARVIDSSON, 1986; DOOREN, BOUCKAERT e HALLIGAN, 2010).

Entretanto, critérios como o de efetividade ou relevância, que levam em conta questões éticas, como o atendimento das demandas sociais, constituindo-se como critérios mais substantivo, acabam por ser esquecidos diante da excessiva ênfase dada aos critérios instrumentais. Nas discussões sobre o desempenho da administração pública, também se fazem presentes autores que criticam a centralidade dos critérios de eficiência ou eficácia no setor público (MOTTA, 1972; MARTINS, 2006; MISOCZKY, 2004).

Merece destaque nesse sentido o trabalho de Benno Sander, que aborda esta questão com profundidade e consistência ao discutir a gestão da educação. Em sua obra Gestão da educação na América Latina, Sander (1995) propõe o seu modelo do paradigma multidimensional com o objetivo de tentar construir um conhecimento interdisciplinar. Em seu modelo, o autor apresenta uma visão mais ampla do desempenho administrativo, que deve 
Choque de gestão ou choque de racionalidades? O desempenho da administração pública em questão

ser mensurado por meio de quatro critérios: eficiência, entendido como a capacidade de produzir mais com menos recursos; eficácia, vista como a capacidade de alcançar os objetivos estabelecidos; efetividade, entendido como a capacidade de atender às demandas da sociedade; e relevância, pensado como um critério que mede o desempenho a partir da importância ou da pertinência, em que a ação está orientada para a melhoria do desenvolvimento humano e da qualidade de vida, sendo facilitado por um processo administrativo participativo e democrático. $\mathrm{O}$ autor relaciona os dois primeiro critérios à idéia de instrumentalidade, e os dois últimos, à substantividade, aproximando-se de Guerreiro Ramos (1989) na medida em que, ao pensar o conceito de desempenho de forma mais ampla, considera não apenas critérios econômicos e instrumentais, mas também critérios sociais e substantivos. Tal aproximação pode ser representada pela Figura 1 a seguir:

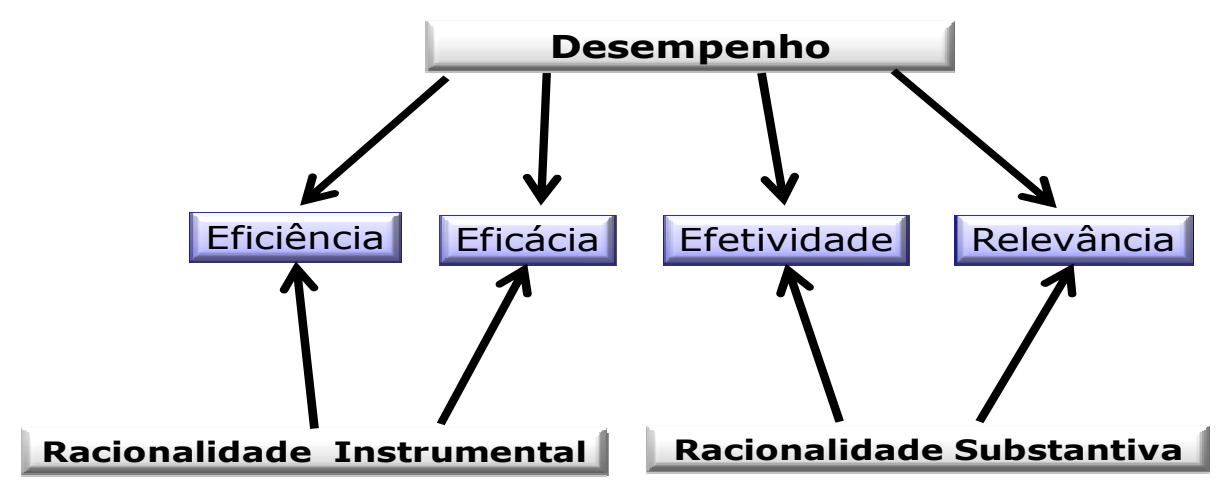

Figura 1- Modelo relacionando o paradigma multidimensional de Benno Sander com as categorias de racionalidade explicitadas por Guerreiro Ramos.

Fonte: elaboração própria dos autores

\section{MÉTODO DE PESQUISA}

A presente pesquisa pode ser classificada como sendo de natureza qualitativa. Segundo Vieira (2006), a pesquisa qualitativa "se fundamenta principalmente em análises qualitativas, caracterizando-se, em princípio, pela não-utilização de instrumental estatístico na análise de dados" (VIEIRA, 2006, p.17).

A análise do programa Choque de Gestão do Governo de Minas Gerais se deu com base no modelo teórico que relaciona as categorias racionalidade instrumental e racionalidade substantiva (GUERREIRO RAMOS, 1989) com o paradigma multidimensional de Sander (1995) apresentado anteriormente.

As categorias de análise utilizadas no presente trabalho foram: instrumentalidade e substantividade. Tais variáveis podem ser definidas de forma operacional e constitutiva. A definição constitutiva "refere-se ao conceito dado por algum autor da variável ou termo que se 
vai utilizar" (VIEIRA, 2006, p. 19). Neste sentido, a partir do referencial teórico aqui utilizado, as definições constitutivas das variáveis utilizadas são:

- Instrumentalidade - A “organização da atividade dos membros da sociedade em função de finalidades objetivas" (MANNHEIM, 1962, p. 68).

- Substantividade - "um ato de pensamento que revele percepção inteligente das inter-relações dos acontecimentos de uma determinada situação". (MANNHEIM, 1962, p. 63).

Já no que diz respeito à definição operacional, Vieira (2006, p. 19) explica que esta "refere-se a como aquele termo ou variável será identificado, verificado ou medido, na realidade". Assim, as definições constitutivas foram operacionalizadas no presente trabalho por meio dos seguintes indicadores:

- Instrumentalidade:

Orientação para eficiência - Pode ser identificada a partir do uso de expressões como "redução de custos", "maximização do uso de recursos", "aumento de produtividade", ou "tornar o Estado mais competitivo", bem como da presença de elementos que indiquem o predomínio de uma lógica de mercado.

Orientação para eficácia - Pode ser identificada a partir do uso de expressões como "foco em resultados", "estabelecimento de metas", ou "alcance de objetivos".

Realização de cálculos - Pode ser identificada a partir das referências feitas tanto no que se refere à escolha como no que tange à melhor utilização de recursos de forma a garantir o alcance dos objetivos estabelecidos.

- Substantividade:

Orientação para efetividade - Pode ser identificada a partir do uso de expressões como "atendimento das demandas (políticas) da sociedade", "solução de problemas da comunidade", "alcance de objetivos sociais", ou "Redução da desigualdade social".

Orientação para relevância - Pode ser identificada a partir do uso de expressões como "com o objetivo de melhorar a qualidade de vida da sociedade", "para a melhoria do desenvolvimento humano", ou "com a participação da sociedade".

Os dados foram coletados por meio de pesquisa documental, a partir do Plano Mineiro de Desenvolvimento Integrado (PMDI), documento do Governo do Estado de Minas Gerais que equivale ao plano estratégico das organizações e é responsável pela definição da estratégia de longo prazo do governo. Optou-se pela análise do PMDI por este se constituir como um documento central do programa Choque de Gestão, servindo de base para os demais 
Choque de gestão ou choque de racionalidades? O desempenho da administração pública em questão

documentos. Considera-se suficiente a análise do referido documento, já que foi a partir dele que os demais documentos, como o GERAES - uma carteira com 30 projetos estruturadores e o Plano Plurianual de Ação Governamental (PPAG) - que contém o GERAES, bem como os demais programas prioritários do governo -, tiveram origem.

O método de análise de dados aqui utilizado é a análise argumentativa, uma forma de análise de conteúdo, a qual consiste em "um exercício de redução de dados onde o texto é codificado em determinadas categorias" (BAUER e GASKELL, 2002, p. 237). A opção pela análise argumentativa se deu porque esta consiste em um método que "tem como objetivo oferecer uma visão metodológica compreensiva da análise das estruturas da argumentação, com propósito de compreender melhor os parâmetros que influenciam os debates públicos" (BAUER e GASKELL, 2002, p. 219). Sendo assim, foi possível fazer uma análise mais profunda e detalhada a respeito do programa Choque de Gestão. Além disso, este método possibilitou compreender como as afirmações se estruturam, avaliando sua consistência (BAUER e GASKELL, 2002), o que permitiu analisar a força dos argumentos que embasam o programa Choque de Gestão. Deve-se ressaltar, entretanto, que este método exige maior cuidado, por envolver a subjetividade do pesquisador ao interpretar os dados. A partir dos indicadores descritos anteriormente, o documento PMDI de 2004-2007 foi analisado, buscando-se dados que demonstrem a presença dos indicadores nos referidos documentos. Para a realização da análise, o documento foi dividido em função das três perguntas nele respondidas: Onde estamos? Aonde pretendemos estar? Como "chegar lá”?

Ao final da análise, foi feita uma avaliação de que indicadores predominam no documento, comparando as partes que o compõem, e quais são as possíveis conclusões que podem ser feitas a partir da presença ou ausência de certos indicadores nas referidas partes.

\section{O PROGRAMA CHOQUE DE GESTÃO}

Os processos de reforma gerencial, postos em prática em vários países no fim do século XX, desencadearam propostas de reformas seguindo a mesma lógica gerencial também em nível estadual. O programa Choque de Gestão, implementado no Estado de Minas Gerais, é um exemplo deste tipo de proposta e merece destaque por ser avaliado de maneira bastante positiva na literatura especializada, servindo de base para a criação de processos semelhantes em outros estados do País.

Segundo Guimarães e Campos (2008), o trabalho diagnóstico e propositivo realizado pelo Banco de Desenvolvimento de Minas Gerais (BDMG) em 2002, denominado "Minas 
Gerais do Século XXI”, foi o desencadeador da idéia de que Minas Gerais necessitava de um "choque de gestão", mencionando o termo pela primeira vez. Tal expressão foi criada com o intuito de levar à reflexão sobre a necessidade de superar o modelo burocrático da administração pública, criticado por sua rigidez e centralização, como explicam Neves et al (2010).

Definido como "um conjunto integrado de políticas de gestão pública orientado para o desenvolvimento" (VILHENA ET AL, 2006, p. 21), o programa Choque de Gestão foi dividido em etapas denominadas de gerações. A Primeira Geração do programa Choque de Gestão guiou-se por uma abordagem dual, tendo suas primeiras medidas duas direções: medidas emergenciais de ajuste à realidade, com os objetivos principais de corrigir a situação econômico-financeira do Estado, reconstruir a máquina administrativa, promover o equilíbrio fiscal e recuperar a capacidade de investimento; e medidas estruturantes, com o objetivo de dar as bases para um novo processo de desenvolvimento econômico e social para o Estado, com a ambição de transformar Minas Gerais no melhor Estado para se viver (VILHENA e MARINI, 2010). Já a Segunda Geração do Choque de Gestão, também conhecida como Estado para Resultados, busca alcançar "um Estado capaz de executar as estratégias governamentais de forma efetiva e eficiente, promovendo a plena conexão entre os gastos públicos e os resultados esperados" (SILVA, 2009). Vale ressaltar que o Estado para Resultados tem um tempo de existência finito, estando planejado para se extinguir em 2011 (GUIMARÃES E CAMPOS, 2009).

Para o alcance dos resultados pretendidos, foi criado um sistema de planejamento em Minas Gerais, que é caracterizado por Guimarães e Almeida (2006) como sendo constituído, principalmente, dos seguintes instrumentos: Plano Mineiro de Desenvolvimento Integrado (PMDI), equivalente ao plano estratégico das organizações e responsável pela definição da estratégia de longo prazo do governo; Plano Plurianual de Ação governamental (PPAG), que se constitui como um desdobramento do PMDI para um período de quatro anos, dentre outros documentos de curto prazo.

Para que fosse possível executar de forma eficiente aquilo que foi planejado, tanto no curto quanto no longo prazo, o Governo de Minas Gerais optou por modernizar sua administração pública, aproximando suas práticas de gestão daquelas do setor privado. Esta mudança se deu em diversas áreas, com especial destaque para as áreas de gestão de pessoas, gestão por resultados e gestão financeira, receptoras das maiores mudanças. 
Choque de gestão ou choque de racionalidades? O desempenho da administração pública em questão

A área de Gestão de Pessoas, considerada de difícil operacionalização no setor público, passou por uma intensa reformulação nos órgãos públicos do Estado de Minas Gerais. A este respeito Lemos e Neves (2008) explicam que um novo padrão de política de recursos humanos foi adotado no Estado, redirecionando seu foco para a meritocracia, a valorização contínua e o desenvolvimento do servidor. Para tal, segundo os autores, todos os planos de carreira foram reestruturados, foi adotada a avaliação de desempenho individual dos servidores efetivos, juntamente com uma política de desenvolvimento dos servidores.

Também no sentido de melhorar o desempenho da administração pública, o Governo de Minas Gerais instituiu novas práticas de gestão por resultados. A este respeito, merece destaque o Acordo de Resultados, iniciativa adotada a partir do programa Choque de Gestão, definido como um "instrumento de pactuação de resultados mediante negociação entre dirigentes de órgãos e entidades do Poder Executivo, bem como dos gerentes das unidades administrativas e autoridades que sobre eles tenham poder hierárquico ou de supervisão". (DUARTE ET AL, 2006, p. 98).

Diante da situação financeira crítica em que se encontrava o Estado de Minas Gerais antes do programa Choque de Gestão, novas práticas de gestão financeira foram implementadas, visando a corrigi-la. Norman e Equipe da SEF (2006) destacam que, em um primeiro momento, as principais medidas adotadas na gestão financeira do Estado de Minas Gerais foram a administração tributária e fiscal com foco no aumento das receitas próprias, sem que fosse necessário o aumento de impostos.

Os resultados do programa Choque de Gestão, avaliados pela maior parte dos autores como muito positivos, são na maior parte das vezes atribuídos às medidas ou instrumentos inovadores adotados pelo Governo de Minas Gerais. Ganham destaque na literatura a criação das Organizações da Sociedade Civil de Interesse Público (OSCIPs), as Parcerias PúblicoPrivadas (PPP), bem como a adoção da governança eletrônica.

Uma das principais marcas do programa Choque de Gestão, as Organizações da Sociedade Civil de Interesse Público (OSCIPs), definidas por Vilhena e Athayde (2005) como organizações de direito privado, sem fins lucrativos e de interesse público, foram adotadas como uma forma de tornar a administração pública do Estado de Minas Gerais mais eficiente. As OSCIPS surgem, assim, como uma nova forma de interação entre o Estado e a sociedade civil (VILHENA e ATHAYDE, 2005).

As Parcerias Público-Privadas (PPP) são outra importante inovação adotada pelo Governo de Minas Gerais a partir do programa Choque de Gestão. Tais parcerias também 
recebem muita atenção e são avaliadas de forma positiva pela maior parte dos autores. Segundo Athayde, Gusmão e Silva (2006), o Programa de Parcerias Público-Privadas do Estado de Minas Gerais ganha destaque por ser o primeiro programa de PPPs criado no País. O estabelecimento de PPPs pode ser justificado pela necessidade de se redefinir o papel da iniciativa privada (VILHENA e ATHAYDE, 2005), bem como pela necessidade de dar continuidade ao investimento estatal e pela busca de maior eficiência na prestação dos serviços públicos (BRITO e SILVEIRA, 2005).

Já a governança eletrônica foi uma iniciativa do Governo de Minas Gerais durante o programa Choque de Gestão, que envolveu o uso de tecnologia para aumentar a eficiência do Estado. Por meio desta ferramenta, o Governo de Minas Gerais visa a obter mais transparência, controle público e participação (RODRIGUES e BRASIL, 2010). Tem como principal exemplo o Portal Minas, que consiste no portal de informações do Governo de Minas Gerais (LAIA, 2006).

\section{O CHOQUE DE GESTÃO EM ANÁLISE}

O PMDI foi elaborado pelo Conselho de Desenvolvimento Econômico e Social CDES, composto por representantes do governo e de vários segmentos da sociedade. Constituindo-se como um planejamento de longo prazo, o documento responde a três grandes perguntas: Onde estamos? Aonde pretendemos estar? Como "chegar lá”?

Para responder à primeira pergunta, que representa um diagnóstico da situação em que se encontrava o Estado de Minas Gerais no momento da elaboração do PMDI, foi apresentado o documento intitulado "Minas Gerais do Século XXI", que está presente de forma resumida no PMDI. Elaborado pelo Banco de Desenvolvimento de Minas Gerais (BDMG), tal documento apresenta um diagnóstico da realidade socioeconômica do Estado de Minas Gerais, servindo de base para a descrição da situação do Estado naquele período.

No que diz respeito ao cenário futuro almejado, é apresentado um conjunto de cenários exploratórios, "com o objetivo de refletir sobre as condições de contorno e as principais variáveis da caminhada de Minas Gerais rumo ao futuro, considerando o contexto de elevado nível de incertezas atual” (PMDI, 2003). Sendo assim, os cenários exploratórios mostram quatro cenários futuros possíveis para o Estado no ano de 2020, destacando as oportunidades e riscos que podem estar presentes no percurso de Minas Gerais rumo ao futuro. A segunda questão também é respondida por meio de uma Visão de Futuro de Longo Prazo, que foi desenvolvida a partir da consulta ao Conselho de Desenvolvimento Econômico e Social 
Choque de gestão ou choque de racionalidades? O desempenho da administração pública em questão

(CDES), aprovada pelo governador Aécio Neves e pelo Colegiado de Gestão Governamental, representando a imagem de aonde se quer chegar. Para o alcance deste cenário desejado, conta-se com a participação da sociedade.

Foram desenvolvidas, ainda, três opções estratégicas e uma Agenda de Prioridades, para que fosse definida a forma como chegar ao cenário desejável. Esta etapa também contou com a participação de executivos-chave do Governo Estadual, bem como de lideranças da sociedade mineira, elaborando-se, assim, uma agenda comum entre eles.

Com base no exposto, para a realização da análise aqui proposta, o documento foi dividido em função das três perguntas nele respondidas: Onde estamos? Aonde pretendemos estar? Como "chegar lá”?

\subsection{Onde estamos?}

O primeiro capítulo do PMDI propõe-se a responder a esta pergunta. Para tal, nele é apresentado um Diagnóstico Sumário do Estado de Minas Gerais. Sendo assim, é com base neste capítulo que será aqui analisada a presença ou a ausência das categorias de instrumentalidade ou de substantividade na visão que se tinha da situação do Estado de Minas Gerias naquele momento, que serviu de base para a elaboração da visão de futuro e dos caminhos para que se chegue lá.

Embora a resposta a essa primeira pergunta não forneça elementos que indiquem de forma direta a lógica que orienta o programa Choque de Gestão, foi possível dela extrair fragmentos que demonstram, mesmo que de forma indireta, o pensamento dominante no qual o programa está pautado. Sendo assim, foi possível identificar a presença tanto de elementos instrumentais quanto de elementos substantivos.

\subsubsection{Instrumentalidade}

Logo ao introduzir o contexto do Estado de Minas Gerais no momento em que o programa teve início, destacam-se elementos que demonstram uma orientação para eficiência, a partir de afirmações como a de que "a economia mineira chegou ao final do século XX com um desempenho acima da média nacional, mas com sinais de perda de dinamismo", bem como a de que "se esse fato não for resolvido com urgência e firmeza, decerto comprometerá gravemente a competitividade de Minas Gerais, em uma época de acirramento da disputa, nacional e internacional, por melhores posições no mercado" (PMDI, 2003, p. 10). A preocupação com a competitividade do Estado, bem como com o seu posicionamento no 
mercado demonstra o predomínio da lógica econômica. Sander (1995) destaca a predominância dessa lógica como uma das características do critério de eficiência, que independe do conteúdo humano e da natureza política das práticas.

Além disso, para caracterizar o cenário do Estado de Minas Gerais, é citada uma reforma fazendária, realizada a partir de 1969 no Estado, que foi responsável pela modernização e saneamento das finanças do Estado. Tal reforma, que, na forma como foi descrita, parece apresentar uma preocupação com redução de custos e maximização de resultados, é tratada de forma muito positiva, já que é considerada como "Tão ou mais decisiva para a atuação desenvolvimentista do Governo de Minas” (PMDI, p. 11). Identificase, assim, novamente uma orientação para eficiência, já que práticas como esta são valorizadas e, mais do que isso, consideradas fundamentais.

Ao discutir a questão da infraestrutura do Estado de Minas Gerais naquele período, destaca-se como uma maneira de desenvolvê-la, a implementação de Parcerias PúblicoPrivadas ou outros modos de financiamento, já que estes "não oneram sobremaneira o poder público estadual" (PMDI, 2003, p. 28). Demonstra-se, assim, uma preocupação com a redução de custos do Estado, ressaltada por Sander (1995) como uma das principais características do critério de eficiência. A análise dos indicadores de instrumentalidade presentes nesta parte do documento é sintetizada no Quadro 1 a seguir:

Quadro 1 - Onde estamos? - Instrumentalidade

\begin{tabular}{|c|c|c|}
\hline Orientação para Eficiência & \multicolumn{1}{|c|}{ Orientação para Eficácia } \\
“A economia mineira de Cálculos \\
do século XX com um desempenho ao final & & \\
acima da média nacional, mas com & & \\
sinais de perda de dinamismo. Se esse & & \\
fato não for resolvido com urgência e & & \\
firmeza, decerto comprometerá & & \\
gravemente a competitividade de & & \\
Minas Gerais" (PMDI, 2003, p. 10) & & \\
Defende-se a implementação de & & \\
Parcerias Público-Privadas ou outros & & \\
modos de financiamento, já que estes & & \\
"não oneram sobremaneira o poder & & \\
público estadual” (PMDI, 2003, p. 28). & & \\
& & \\
\hline
\end{tabular}

Fonte: Elaboração própria dos autores com base no documento PMDI (2003)

\subsubsection{Substantividade}


Choque de gestão ou choque de racionalidades? O desempenho da administração pública em questão

Entretanto, elementos substantivos também se mostraram presentes. O critério de relevância, caracterizado por Sander (1995) como um critério que revela a busca por aumento da qualidade de vida e do desenvolvimento humano, mostrou-se presente por meio de uma declaração direta de preocupação com a melhoria da qualidade de vida, que se reflete nos indicadores sociais. O objetivo de alcançar um desenvolvimento sustentável também pode ser identificado, a partir da afirmação de que "reverter esse quadro, ressaltando o poder de ação e reação do Estado e recolocando Minas Gerais de volta ao caminho do desenvolvimento sustentável é desafio que, mais uma vez em sua história, não intimida os mineiros" (PMDI, 2003, p.11). Tal preocupação revela, mais uma vez, a presença da orientação para a relevância, critério que se expressa pela busca do desenvolvimento.

A orientação para a relevância também é observada quando se discorre a respeito do papel do Estado. Considerado como um ator central, o Estado deve atuar, conforme defendese no documento, "incentivando a participação da sociedade civil organizada" (PMDI, 2003, p. 20). Merece destaque a importância da participação social para o critério de relevância, destacada por Sander (1995) como um requisito para que o alcance da relevância se dê.

A preocupação com a solução de problemas da comunidade também se apresenta aí como um indicador de orientação para a efetividade, tendo em vista que também é reforçada a idéia de que o Estado deve agir "provendo os serviços e equipamentos sociais imprescindíveis ao bem-estar da população" (PMDI, 2003, p. 20).

Além disso, observou-se, no plano, uma visão mais ampla de desenvolvimento, que vai além da lógica puramente econômica e demonstra também uma preocupação com a qualidade de vida, característica do critério de relevância, bem como com o atendimento de demandas sociais, como o acesso à educação e a saúde, ou o fim das desigualdades sociais, que representam a orientação para a efetividade. Tal preocupação é expressa a partir de afirmações tais como a de que "o novo desenvolvimento não é sinônimo apenas de crescimento econômico, nem de riqueza ou mesmo de renda per capita, fenômenos de fácil percepção e classicamente mensurados por índices conhecidos", mas que "o desenvolvimento é sustentável quando promove a prosperidade econômica e mostra novas faces, como educação e saúde, com a atenuação das desigualdades sociais e o equilíbrio ambiental" (PMDI, 2003, p. 12). A análise dos indicadores de substantividade presentes nesta parte do documento é sintetizada no Quadro 2 a seguir:

Quadro 2 - Onde estamos? - Substantividade 
Vanessa Brulon, Marcelo Milano Falcão Vieira (in memoriam) \& Leonardo Darbilly

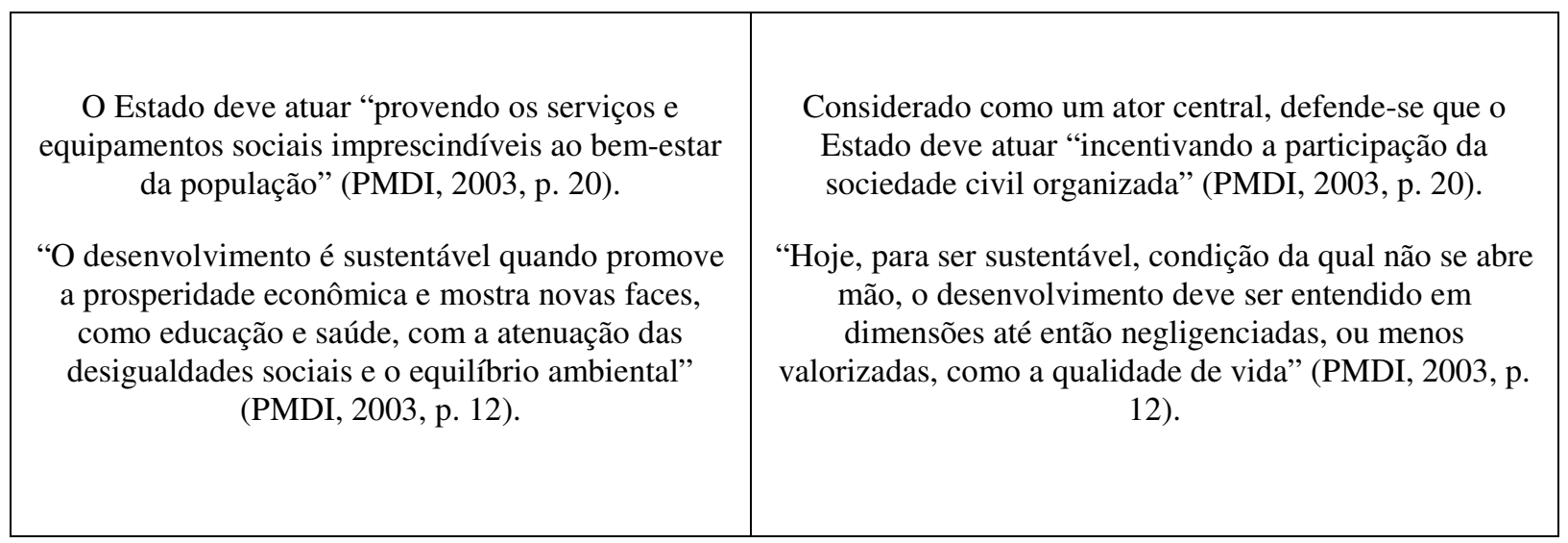

Fonte: Elaboração própria dos autores com base no documento PMDI (2003)

Observa-se, assim, um equilíbrio entre elementos instrumentais e substantivos como orientadores do programa Choque de Gestão. Com base nos elementos presentes nesta parte do documento percebe-se que nos objetivos almejados também estão contidos desejos de melhoria da qualidade de vida ou de atendimento das demandas sociais. E ainda, a idéia de desenvolvimento que guia o PMDI é bastante ampla, englobando todos os aspectos aqui trabalhados.

\subsection{Aonde pretendemos estar?}

A resposta a esta pergunta se dá em duas etapas. Na primeira, representada pelo segundo capítulo do Plano, são apontados os Cenários Exploratórios do Estado de Minas Gerais de 2003 - 2020. Em seguida, no capítulo 3, são apresentadas as aspirações para o futuro de Minas Gerais a longo prazo, e no capítulo 4, a visão de futuro para 2020 é consolidada, também com o intuito de se demonstrar aonde se quer chegar.

\subsubsection{Instrumentalidade}

No que diz respeito aos Cenários Exploratórios do Estado, estes são imagens de possíveis futuros para o Estado de Minas Gerais nos próximos 20 anos, "visando possibilitar uma análise prospectiva do Estado, ou seja, uma reflexão sistemática que visa orientar a ação presente à luz dos futuros prováveis" (PMDI, 2003, p. 32). Sendo assim, eles indicam a realização de cálculos, na medida em que consistem na apresentação de todas as possibilidades, para que a partir de sua análise seja possível optar pela melhor utilização de recursos de forma a garantir o alcance dos objetivos estabelecidos. Esta idéia também pode ser observada a partir da afirmação de que a análise prospectiva "possibilita a antecipação de oportunidades, ameaças e desafios que devem ser focalizados nas agendas estratégicas do

REAd I Porto Alegre - Edição 74 - N 1 - jan/abr 2013 - p. 1-34 
Choque de gestão ou choque de racionalidades? O desempenho da administração pública em questão

Governo do Estado e dos demais atores integrantes da sociedade mineira" (PMDI, 2003, p. 33). A realização de cálculos, como mostraram Kalberg (1980) e Guerreiro Ramos (1989), é característica de uma lógica instrumental.

Ao descrever os estados possíveis da reforma do Estado no tocante à gestão pública e ao equacionamento fiscal, o documento apresenta como o melhor cenário, que corresponde ao extremo "eficiente e competitivo", aquele no qual o programa Choque de Gestão é bem sucedido, como um cenário no qual "O equacionamento fiscal é alcançado de forma estrutural, com obediência total à Lei de responsabilidade fiscal” (PMDI, 2003, p. 53), além de ser estabelecida "a criação de um novo marco legal, (que) favorece o estabelecimento de frutíferas Parcerias Público-Privadas - PPP. Como resultado, ocorre grande redução da relação custo/benefício do serviço público estadual” (PMDI, 2003, p. 53). Diante disto, o cenário ideal é descrito como um cenário de redução de custos e maximização de resultados, indicando uma orientação para eficiência.

Também está presente na descrição do cenário ideal a orientação para eficácia. Tal orientação mostrou-se presente na afirmação de que com o sucesso do programa Choque de Gestão "é formada uma nova mentalidade no serviço público, baseada no empreendedorismo e voltada para resultados" (PMDI, 2003, p. 53). Este pensamento demonstra que as ações colocadas em prática por meio do programa Choque de Gestão estão orientadas para o alcance de metas estabelecidas, característica do critério de eficácia descrito por Sander (1995).

A partir da descrição do que é considerado o cenário mais favorável para o Estado de Minas Gerais em 2020, identificado como "conquista do melhor futuro", é possível perceber a lógica que orienta o programa. Dentro deste cenário, “o Estado de Minas Gerais constrói uma trajetória de prosperidade econômica, melhoria social e revigoramento político, ocupando espaços e assumindo posição de liderança na esfera nacional” (PMDI, 2003, p. 56). No cenário descrito, estão presentes elementos instrumentais, já que se pode observar a presença de uma lógica econômica, atrelada à orientação para eficiência.

Ainda, na descrição deste cenário, a orientação para eficiência e eficácia é demonstrada de forma direta, ao se afirmar que "do lado do setor público, predominam a eficiência e a eficácia da gestão, proporcionadas por um 'Choque de Gestão' amplo em todos os poderes e pelo equacionamento fiscal do Estado de forma estrutural" (PMDI, 2003, p. 57).

Nos capítulos 3 e 4, que tratam das aspirações para o futuro de Minas Gerias a longo prazo e da visão de futuro para 2020, respectivamente, e que também se propõem a responder à questão sobre aonde se quer chegar, também podem ser observados elementos que indicam 
instrumentalidade. Os elementos instrumentais estão presentes quando se afirma que "a gestão pública se reestrutura, reduzindo fortemente a relação custo/benefício do investimento público", ocorrendo, ao mesmo tempo, "a aproximação entre os setores público e privado, predominando o diálogo construtivo do Governo com a livre iniciativa e o estabelecimento de frutíferas e sólidas parcerias”. (PMDI, 2003, p. 73). Observa-se, assim, que no futuro de longo prazo do Estado deve ser alcançada uma redução de custos, por meio, por exemplo, de parcerias com o setor privado. Tal característica indica a orientação para a eficiência, como mostrou Sander (1995).

A análise dos indicadores de instrumentalidade presentes nesta parte do documento são sintetizados no Quadro 3 a seguir:

Quadro 3 - Aonde pretendemos estar? - Instrumentalidade

\begin{tabular}{|c|c|c|}
\hline Orientação para Eficiência & Orientação para Eficácia & Realização de Cálculos \\
\hline $\begin{array}{l}\text { No melhor cenário defende-se } \\
\text { “o estabelecimento de } \\
\text { frutíferas Parcerias Público- } \\
\text { Privadas - PPP. Como } \\
\text { resultado, ocorre grande } \\
\text { redução da relação } \\
\text { custo/benefício do serviço } \\
\text { público estadual" (PMDI, } \\
\text { 2003, p. 53). } \\
\text { No futuro desejado, "A gestão } \\
\text { pública se reestrutura, } \\
\text { reduzindo fortemente a relação } \\
\text { custo/benefício do } \\
\text { investimento público, ao } \\
\text { mesmo tempo em que ocorre a } \\
\text { aproximação entre os setores } \\
\text { público e privado, (...). } \\
\text { (PMDI, 2003, p. 73). }\end{array}$ & $\begin{array}{c}\text { Com o sucesso do programa “é } \\
\text { formada uma nova } \\
\text { mentalidade no serviço } \\
\text { público, baseada no } \\
\text { empreendedorismo e voltada } \\
\text { para resultados" (PMDI, 2003, } \\
\text { p. 53). } \\
\text { “Do lado do setor público, } \\
\text { predominam a eficiência e a } \\
\text { eficácia da gestão, } \\
\text { proporcionadas por um } \\
\text { 'Choque de Gestão' amplo em } \\
\text { todos os poderes e pelo } \\
\text { equacionamento fiscal do } \\
\text { Estado de forma estrutural, } \\
\text { com obediência à totalidade da } \\
\text { Lei de Responsabilidade } \\
\text { Fiscal” (PMDI, 2003, p. 57). }\end{array}$ & $\begin{array}{l}\text { São elaborados Cenários Exploratórios, } \\
\text { "visando possibilitar uma análise prospectiva } \\
\text { do Estado, ou seja, uma reflexão sistemática } \\
\text { que visa orientar a ação presente à luz dos } \\
\text { futuros prováveis" (PMDI, 2003, p. 32). } \\
\text { A análise prospectiva “possibilita a } \\
\text { antecipação de oportunidades, ameaças e } \\
\text { desafios que devem ser focalizados nas } \\
\text { agendas estratégicas do Governo do Estado e } \\
\text { dos demais atores integrantes da sociedade } \\
\text { mineira" (PMDI, 2003, p. 33). }\end{array}$ \\
\hline
\end{tabular}

Fonte: Elaboração própria dos autores com base no documento PMDI (2003)

\subsubsection{Substantividade}

Mas no cenário ideal para Minas Gerais em 2020, também está presente uma preocupação com a melhoria social do Estado. A busca pelo alcance de objetivos sociais, que a descrição do melhor cenário parece indicar, corresponde à orientação para efetividade.

Há, ainda, um predomínio de elementos substantivos na "conquista do melhor futuro" a ser alcançado pelo programa Choque de Gestão. O objetivo de se reduzir a desigualdade social é bastante enfatizado por meio de afirmativas tais como a de que "espacialmente, Minas Gerais consegue diminuir progressivamente suas dramáticas desigualdades regionais com políticas específicas de redução dos estrangulamentos nas regiões mais carentes e REAd I Porto Alegre - Edição 74 - N 1 - jan/abr 2013 - p. 1-34 
Choque de gestão ou choque de racionalidades? O desempenho da administração pública em questão

fortalecimento das vocações e economias locais" (PMDI, 2003, p. 57). A presença de tal elemento pode ser considerada, como mostrou Sander (1995), um indicador de orientação para a efetividade. Atrelado ao objetivo de redução das desigualdades sociais está o foco na melhoria da qualidade de vida da população mineira. Esta idéia é explicitada no fragmento o qual afirma que "na área social, aumenta o acesso da população a serviços de saúde de qualidade ao mesmo tempo em que se expandem e melhoram as condições de habitação e de qualidade de vida do povo mineiro" (PMDI, 2003, p. 58).

Pode-se observar, assim, mais uma vez, a orientação para efetividade ao se demonstrar novamente a meta de se reduzir as desigualdades regionais e sociais, bem como a preocupação com o alcance de objetivos sociais, como a expansão dos serviços de saúde ou a melhoria das condições de habitação. Mas atrelado a isso, também está presente a orientação para relevância, quando se trata da preocupação com a melhoria de vida da população. Tais fatores expressam o objetivo maior de tornar "Minas Gerais o melhor estado para se viver".

Mesmo ao descrever o cenário de "desperdício de oportunidades", cenário em que o Estado de Minas Gerais não consegue aproveitar as oportunidades em contexto nacional, os elementos substantivos mostraram-se presentes. Afirma-se, assim, que "na área social, o sistema educacional alcança a universalização do ensino fundamental e grande ampliação do ensino médio, ao passo que ocorrem apenas melhorias incrementais de qualidade" e que "na saúde, são ampliadas as condições de acesso aos serviços públicos, mas estes perdem em qualidade" (PMDI, 2003, p. 60).

Novamente observa-se a orientação para efetividade, a partir da meta de ampliação do sistema educacional e da saúde, mesmo que isto não se dê de forma plena. Da mesma forma, está presente a orientação para relevância, a partir da preocupação com o aumento da qualidade de vida. Já no que diz respeito aos piores cenários de "superação de adversidades" e de "decadência e empobrecimento" as preocupações se mantém, mesmo diante dos enormes obstáculos para alcançá-las.

A presença de elementos substantivos mostra-se mais forte no cenário futuro desejado para o Estado. O objetivo de melhorar o desenvolvimento humano, que indica uma orientação para relevância, apresenta-se na preocupação com o aumento de indicadores sociais, como o Índice de Desenvolvimento Humano (IDH). Defende-se que, neste cenário futuro, "O círculo virtuoso de crescimento reflete-se em indicadores sociais extremamente positivos, com o Índice de Desenvolvimento Humano - IDH alcançando, em 20 anos, valores comparáveis aos de Portugal em 2000 e da Espanha em 1990”. 
A orientação para efetividade também pode ser observada por meio da preocupação em atender às demandas sociais de forma mais ampla em um contexto futuro. Considera-se, por exemplo, que políticas sociais relacionadas ao emprego, microcrédito, combate à fome e bolsa-escola "são aliadas ao sentimento solidário do mineiro que, em uma parceria virtuosa, colocam o Estado no cenário mundial em relação ao desenvolvimento de modelos de intervenção comunitária no combate à pobreza" (PMDI, 2003, p. 73). Idéias semelhantes são expressas ao se descrever a área da saúde, da segurança, ou da educação, por exemplo. A análise dos indicadores de instrumentalidade presentes nesta parte do documento são sintetizados no Quadro 4 a seguir:

Quadro 4 - Aonde pretendemos estar? - Substantividade

\begin{tabular}{|c|c|}
\hline Orientação para Efetividade & Orientação para Relevância \\
\hline $\begin{array}{c}\text { No "melhor futuro", "espacialmente, Minas Gerais } \\
\text { consegue diminuir progressivamente suas dramáticas } \\
\text { desigualdades regionais (...)" (PMDI, 2003, p. 57). }\end{array}$ & $\begin{array}{c}\text { "O círculo virtuoso de crescimento reflete-se em } \\
\text { indicadores sociais extremamente positivos, com o } \\
\text { Índice de Desenvolvimento Humano - IDH }\end{array}$ \\
"As políticas sociais ativas de emprego, o & alcançando, em 20 anos, valores comparáveis aos de \\
Portugal em 2000 e da Espanha em 1990" (PMDI, \\
microcrédito, o combate à fome e a bolsa-escola são \\
aliadas ao sentimento solidário do mineiro que, em \\
uma parceria virtuosa, colocam o Estado no cenário \\
mundial em relação ao desenvolvimento de modelos \\
de intervenção comunitária no combate à pobreza" \\
(PMDI, 2003, p. 73).
\end{tabular}

Fonte: Elaboração própria dos autores com base no documento PMDI (2003)

É neste sentido que se pode afirmar que a visão do futuro do Estado de Minas Gerais para 2020 é uma visão extremamente positiva, que contém metas sociais, como, por exemplo, a expansão do sistema educacional, de saúde e de segurança, a busca por melhoria da qualidade de vida e do desenvolvimento humano, e, ainda, objetivos de redução de custos e aumento da eficiência e da eficácia do Estado. Sendo assim, elementos substantivos e instrumentais coexistem no Estado de Minas Gerais do ano de 2020, que se pretende alcançar por meio do programa Choque de Gestão.

\subsection{Como “chegar lá”?}

Para responder a esta pergunta, em primeiro lugar, são apresentadas três opções estratégicas que estruturarão as iniciativas e ações do Governo de Minas Gerais. No quinto capítulo do PMDI, tais estratégias são identificadas como: promover o desenvolvimento 
Choque de gestão ou choque de racionalidades? O desempenho da administração pública em questão

econômico e social em bases sustentáveis; reorganizar e modernizar a administração pública estadual; e recuperar o vigor político.

\subsubsection{Instrumentalidade}

$\mathrm{Na}$ busca do cenário descrito, que contém elementos instrumentais e substantivos, pautando-se em um conceito amplo de desenvolvimento, observa-se o predomínio de elementos instrumentais. As formas de se alcançar o futuro proposto indicadas no Plano demonstram a orientação para eficiência e eficácia, bem como a realização de cálculos. Acredita-se que, para se "chegar lá", "torna-se urgente fazer funcionar, reorganizar e modernizar o aparato institucional, colocando em prática um 'Choque de Gestão' em suas estruturas, sistemas e processos administrativos" o qual "possibilite descomplicar procedimentos, racionalizar gastos e produzir mais resultados com os recursos disponíveis" (PMDI, 2003, p. 84). Demonstra-se, assim, a preocupação com a redução de custos, o foco em resultados, pensando-se na melhor utilização de recursos de forma a garantir o alcance dos objetivos propostos. A orientação para eficiência, a orientação para a eficácia e a realização de cálculos são vistas como questões centrais no alcance do cenário descrito.

Ainda para responder a como "chegar lá", são descritos no capítulo 6 os objetivos prioritários do governo, explicitando-se as orientações estratégicas específicas para a realização de cada um desses objetivos. Tais objetivos prioritários englobam a melhoria da segurança, da infraestrutura, da qualidade da educação, saúde e habitação, bem como a geração de empregos, o aumento do desenvolvimento econômico, a redução da desigualdade social, dentre outras metas que vão ao encontro da visão de futuro explicitada. Isto significa que há a coexistência entre elementos substantivos, como os objetivos sociais, e elementos instrumentais, que se evidenciam, por exemplo, por meio do objetivo de "estabelecer um novo modo de operação do Estado, saneando as finanças públicas e buscando a eficácia da máquina pública, por meio de um efetivo "choque de gestão"”.

Ao descrever as estratégias para que estes objetivos sejam alcançados, demonstra-se, mais uma vez, o foco em elementos predominantemente instrumentais. Quando se discute o objetivo de "melhoria e ampliação dos serviços públicos", por exemplo, os elaboradores do documento afirmam que "gestores de entidades que prestam serviços estaduais ao público, com destaque para a área social” devem "conseguir, com melhor gerenciamento (...) viabilizar formas consistentes para produzir mais com os recursos já disponíveis e/ou captar recursos para custear a ampliação da oferta, junto a fontes alternativas” (PMDI, 2003, p. 91). Tal 
afirmação demonstra de forma direta a orientação para eficiência como meio para se "chegar lá”. A redução de gastos, o uso mínimo de recursos, explicitados neste fragmento do documento, são características do critério de eficiência descrito por Sander (1995).

Ao se discutir o objetivo de "choque de gestão", é explicitado de forma bastante enfática o foco em equilíbrio fiscal e, conseqüentemente, na redução dos gastos do governo, como no extrato em que se afirma que "antes de tudo, será preciso alcançar o equilíbrio fiscal, praticando a disciplina financeira sem a menor concessão", sendo que "o orçamento será um instrumento efetivo de gestão com programação e execução confiáveis e previsíveis, o que significa menos riscos para os fornecedores, logo, com maiores margens para redução de custos”. (PMDI, 2003, p. 99). O predomínio da lógica econômica torna-se ainda mais explícito no trecho do documento no qual se afirma que "em segundo lugar, se impõe intensificar o esforço de geração de receitas e, especialmente, de melhoria da arrecadação da receita gerada, qualquer que seja sua natureza", sendo preciso "concentrar atenção na melhoria da arrecadação de tributos, inclusive estimulando todas as empresas sediadas em Minas a arrecadarem aqui". (PMDI, 2003, p. 100). Defende-se, ainda, que "é dever prioritário de cada integrante deste Governo, desde o primeiro até o menor dos escalões, zelar por uma melhor qualidade do gasto" (PMDI, 2003, p. 100). Diante do que se considera como "melhor qualidade do gasto", descrita no plano como "um melhor planejamento de prioridades, menor propensão à pulverização e maior atenção aos custos" (PMDI, 2003, p. 100), também se observa a orientação para a eficiência.

Há grande foco, ainda, na modernização e inovação da gestão pública, que "ganha relevância estratégica pelos seus efeitos multiplicadores e integradores, além da redução de custos que poderá propiciar em decorrência de racionalizações de várias ordens" (PMDI, 2003, p. 101). Conclui-se, assim, que a "modernização da infra-estrutura física, tecnológica e organizacional da administração pública estadual” (PMDI, 2003, p. 101) é levantada como uma das prioridades do governo ao adotar o programa Choque de Gestão, tendo em vista, principalmente, a redução de custos por ela proporcionada.

Tais elementos indicam uma orientação para eficiência, já que esta enfatiza a redução de custos e o predomínio de uma lógica econômica. Mas a orientação para a eficácia também pode ser observada. Na implementação do programa Choque de Gestão, em busca do futuro descrito, é levantada como uma das prioridades do governo a "Disseminação da prática de implementação e gerenciamento de projetos e de programas focados em resultados, com atribuição de prioridades aos 'Projetos Estruturadores' do Governo" (PMDI, 2003, p. 101). 
Choque de gestão ou choque de racionalidades? O desempenho da administração pública em questão

Ressalta-se, assim, o foco em resultados como um dos principais orientadores das ações do governo, o que demonstra uma orientação para a eficácia.

Desta forma, o predomínio de elementos instrumentais é observado por meio de muitos fragmentos do documento, que demonstram a predominância de uma lógica de mercado e enfatizam a redução de custos ou o foco em resultados. Essa idéia fica ainda mais explícita com a conclusão de que "é fundamental que o Estado disponha de profissionais capazes de assumir compromissos com a obtenção de resultados, a racionalização de custos e o empenho profissional", assim como "em relação à missão, aos valores e aos objetivos do serviço público" (PMDI, 2003, p. 101). A análise dos indicadores de instrumentalidade presentes nesta parte do documento são sintetizados no Quadro 5 a seguir:

Quadro 5 - Como “chegar lá”? - Instrumentalidade

\begin{tabular}{|c|c|c|}
\hline Orientação para Eficiência & Orientação para Eficácia & Realização de Cálculos \\
\hline $\begin{array}{l}\text { Deve-se colocar “em prática um } \\
\text { ‘Choque de Gestão' (...) que } \\
\text { possibilite descomplicar } \\
\text { procedimentos, racionalizar gastos } \\
\text { e produzir mais resultados com os } \\
\text { recursos disponíveis” (PMDI, } \\
\text { 2003, p. 84). } \\
\text { “Um desafio particularmente } \\
\text { relevante (...) é conseguir, com } \\
\text { melhor gerenciamento (...) } \\
\text { viabilizar formas consistentes para } \\
\text { produzir mais com os recursos já } \\
\text { disponíveis (...)” (PMDI, 2003, p. } \\
\text { 91). } \\
\text { “Antes de tudo, será preciso } \\
\text { alcançar o equilíbrio fiscal, } \\
\text { praticando a disciplina financeira } \\
\text { sem a menor concessão”(PMDI, } \\
\text { 2003, p. 99). }\end{array}$ & $\begin{array}{l}\text { É levantada como uma das } \\
\text { prioridades do governo a } \\
\text { "Disseminação da prática de } \\
\text { implementação e gerenciamento de } \\
\text { projetos e de programas focados } \\
\text { em resultados, com atribuição de } \\
\text { prioridades aos 'Projetos } \\
\text { Estruturadores' do Governo" } \\
\text { (PMDI, 2003, p. 101). } \\
\text { "É fundamental que o Estado } \\
\text { disponha de profissionais capazes } \\
\text { de assumir compromissos com a } \\
\text { obtenção de resultados(...)”(PMDI, } \\
\text { 2003, p. 101). }\end{array}$ & \\
\hline
\end{tabular}

Fonte: Elaboração própria dos autores com base no documento PMDI (2003)

\subsubsection{Substantividade}

Apesar do predomínio de elementos instrumentais ao se pensar nos caminhos para se chegar lá, pode-se identificar também um interesse de participação social no processo e um forte desejo de mobilizar a sociedade civil, a partir de afirmações como: "Mais uma vez, invoca-se a participação direta da sociedade civil organizada por meio de entidades 
empresariais e de trabalhadores, e de organizações não governamentais" (PMDI, 2003, p. 93). Segundo Sander (1995), é somente por meio da participação da sociedade que o critério de relevância pode ser alcançado.

A análise dos indicadores de substantividade presentes nesta parte do documento são sintetizados no Quadro 6 a seguir:

Quadro 6 - Como "chegar lá”? - Substantividade

\begin{tabular}{|l|c|}
\hline Orientação para Efetividade & \multicolumn{1}{|c|}{ Orientação para Relevância } \\
\hline & "Mais uma vez, invoca-se a participação direta da \\
sociedade civil organizada por meio de entidades \\
empresariais e de trabalhadores, e de organizações \\
não-governamentais" (PMDI, 2003, p. 93).
\end{tabular}

Fonte: Elaboração própria dos autores com base no documento PMDI (2003)

Pode-se, então, concluir a partir da análise da parte final do documento que, apesar de se ter como objetivo o alcance de um futuro para o Estado de Minas Gerais em que predominem elementos substantivos, como o atendimento das demandas sociais, a melhoria da qualidade de vida da população, o aumento do desenvolvimento humano, propondo, para isso, a participação da sociedade civil neste processo, os meios para alcançar este fim são predominantemente instrumentais. É por meio da redução de custos e dos gastos do governo, do foco em resultados, e seguindo-se uma lógica predominantemente econômica que se pretende fazer de Minas o melhor estado para se viver.

\section{CONSIDERAÇÕES FINAIS}

O predomínio da lógica instrumental em todas as esferas da vida humana também se reflete no setor público. É dentro deste contexto que o conceito de desempenho da administração pública é pensado a partir de uma visão restrita, que considera apenas os critérios de eficiência e eficácia. Em defesa da retomada da racionalidade substantiva, no presente trabalho propõe-se que o conceito de desempenho, principalmente no que se refere à área pública, seja pensado de forma mais ampla, incluindo-se também critérios substantivos, 
Choque de gestão ou choque de racionalidades? O desempenho da administração pública em questão

como a relevância e a efetividade. Nesse sentido, o trabalho teve como objetivo analisar em que medida o programa Choque de Gestão, do Governo do Estado de Minas Gerais, compreende as diferentes dimensões de desempenho.

A partir da analisa realizada, pode-se perceber que, ao responder as perguntas "Onde estamos?" e “Aonde pretendemos estar?", houve um equilíbrio entre elementos substantivos e instrumentais, com o predomínio de elementos substantivos, em alguns momentos. Foi possível destacar fragmentos que indicam a presença da lógica econômica, como na preocupação em transformar Minas Gerais em um estado competitivo, bem como de orientação para eficiência e eficácia, como na declarada intenção de se adotar Parcerias Público-Privadas para redução de custos, e na orientação para resultados. Mas a preocupação com elementos como a qualidade de vida e o desenvolvimento humano, a redução das desigualdades sociais e o estímulo à participação social, demonstram uma orientação para efetividade e relevância. Merece destaque o conceito de desenvolvimento que é definido nesta parte do documento. A partir da definição apresentada, o conceito de desenvolvimento que guia o programa é pensado de forma ampla, englobando elementos instrumentais, como a presença de uma lógica econômica, mas também de elementos substantivos, como a preocupação com a qualidade de vida e com o atendimento das demandas sociais.

Já no que diz respeito aos "caminhos" para se "chegar lá", a presença de elementos substantivos não é tão constante assim. Tais elementos se mostram presentes apenas ao se demonstrar o estímulo à participação da sociedade para o alcance da visão de futuro proposta. As demais medidas sugeridas, como a redução de custos, que deve ser obtida por meio de Parcerias Público-Privadas, o foco em resultados, ou do saneamento das finanças públicas, por exemplo, giram em torno da eficiência e da eficácia.

Observa-se, assim, que, para transformar Minas Gerais no melhor estado para se viver, com o alcance de objetivos substantivos, optou-se, por meio do programa Choque de Gestão, pela adoção de medidas predominantemente instrumentas na administração pública mineira.

O cenário futuro descrito no PMDI foi definido a partir de discussões entre os membros do Conselho de Desenvolvimento Econômico e Social - CDES, composto por representantes do governo e de vários segmentos da sociedade. Como forma de conciliar os interesses dos diferentes grupos envolvidos no processo, o cenário final foi descrito como um futuro em que as demandas de todos os setores da sociedade seriam atendidas, e Minas efetivamente alcançaria um patamar de melhor estado para se viver. 
Entretanto, apesar de a visão de futuro descrita contemplar elementos substantivos de forma ampla, o documento PMDI já possui uma orientação instrumental de partida, por consistir em um planejamento estratégico, desenvolvido com base nos métodos utilizados pelas empresas privadas. O primeiro passo no alcance do cenário futuro descrito foi a elaboração do planejamento estratégico, ferramenta instrumental disseminada no setor privado, representada neste caso pelo próprio documento objeto de análise.

Faz-se relevante, assim, refletir a respeito da forte presença de elementos substantivos em um documento que conta com uma instrumentalidade de partida. O problema se dá, principalmente, devido a uma forte contradição entre os conceitos de desenvolvimento, no qual está pautada a visão de futuro estabelecida, e de desempenho, a partir do qual são propostas as medidas a serem adotadas para o alcance do cenário futuro.

Como pode ser verificado na análise, o conceito de desenvolvimento orientador do PMDI está impregnado de elementos substantivos, como a preocupação com a qualidade de vida ou com o atendimento das demandas sociais. Entretanto, o conceito de desempenho em que está pautado engloba aspectos predominantemente instrumentais, já que se acredita que para que a administração pública mineira melhore seu desempenho basta que ela adote medidas como a redução de custos ou o foco em resultados.

Sendo assim, apesar de se guiar por uma visão de futuro que representa um estado em que estão presentes as duas categorias aqui trabalhadas, as idéias que orientam as práticas que devem ser desempenhadas para o alcance de tal cenário são predominantemente instrumentais. Por isso, respondendo ao objetivo da presente pesquisa, conclui-se que o conceito de desempenho em que se pauta o programa Choque de Gestão não compreende as diferentes dimensões de desempenho de forma equilibrada, apesar de se guiar por um conceito de desenvolvimento que envolve elementos substantivos e instrumentais na mesma proporção. Em meio a esse descompasso de conceitos, racionalidade substantiva e instrumental se chocam, e o resultado não pode ser positivo.

As conclusões aqui apresentadas oferecem fundamentos, assim, para que o modelo atual da administração pública seja discutido de forma crítica, levantando questões que devem ser repensadas para que a administração pública cumpra sua função social. Ao colocar em questão as práticas da administração pública atual e discutir sua adequabilidade, traz reflexões que podem fornecer bases para a construção de um modelo de administração pública que permita a efetiva realização do bem comum, reduzindo as desigualdades. 
Choque de gestão ou choque de racionalidades? O desempenho da administração pública em questão

Não obstante a relevância do tema para o contexto atual, o presente trabalho apresenta algumas limitações. Em primeiro lugar, o método de análise argumentativa utilizado envolve a subjetividade do pesquisador, o que pode prejudicar a interpretação dos dados. Buscando amenizar esta limitação, o presente trabalho foi debatido com outros pesquisadores, reduzindo-se, assim, a possibilidade do viés por meio do debate. Além disso, por tratar-se de uma pesquisa documental, o trabalho torna-se limitado à interpretação do autor sobre o texto. Diante disso, todos os cuidados necessários foram tomados para que a pesquisa não envolvesse uma decisão política, mas que se desse com base em uma bibliografia consistente. Parte-se, isto sim, de alguns pressupostos, que já foram explicitados ao longo do trabalho. Para que se avance diante desta questão, fica aqui a sugestão de que o programa Choque de Gestão seja investigado na prática, para que se verifique, por exemplo, se aquilo que foi formulado por meio do Plano Mineiro de Desenvolvimento Integrado (PMDI) está efetivamente ocorrendo ou se por meio das medidas instrumentais propostas pelo programa Choque de Gestão está sendo possível o alcance da visão de futuro formulada.

\section{REFERENCIAS}

ARVIDSSON, G. Performance Evaluarion. In: KAUFMANN, F. X.; MAJONE, G.; e OSTROM, V. Guidence, control, and evaluation in the public sector. Berlim and New York: de Gruyter, 1986.

BARROS, M. J. F.; PASSOS, E. S.. Remando a favor da maré: racionalidade instrumental no curso de administração de empresas. Organizações e Sociedade, O\&S, Salvador, 7 (19): 161174, Set/dez, 2000.

BAUER, M. W.; GASKELL, G. Pesquisa qualitativa como texto, imagem e som: um manual prático. 3. Ed. Petrópolis: Vozes, 2002.

BRESSER-PEREIRA, L. C.. Da administração pública burocrática à gerencial. In: BRESSER-PEREIRA, L. C.; SPINK, P.. Reforma do Estado e administração pública gerencial. 7. Ed.. Rio de Janeiro: FGV, 2006.

BRITO, B. M. B.; SILVEIRA, A. H. P. Parceria público-privada: compreendendo o modelo brasileiro. Revista do Serviço Público, RSP, Brasília, 56 (1): 7-21, jan./mar., 2005. 
Vanessa Brulon, Marcelo Milano Falcão Vieira (in memoriam) \& Leonardo Darbilly

CALDERA, R.; TELLOS, J. The Universal Common Good and International Social Justice. The Review of Politics, Indiana, Vol. 38, N. 1, p. 27-39, jan., 1976.

DORREN, W. V.; BOUCKAERT, G.; HALLIGAN, J. Performance management in the public sector. New York: Routledge, 2010.

DOUGLASS, B. The common good and the public interest. Political Theory, SAGE, Illinois, 8(1): 103-117, Feb. 1980.

DUARTE, K.; LEMOS, C.; MARINI, C.; MARTINS, H. F. Acordo de resultados. In: VILHENA, R.; MARTINS, H. F.; MARINI, C.; GUIMARÃES, T. B. O choque de gestão em Minas Gerais: políticas da gestão pública para o desenvolvimento. Belo Horizonte: UFMG, 2006.

DUPRÉ, Louis. The common good and the open society. The Review of politics, Indiana, 55 (4): 687 - 712, Autumn, 1993.

EISEN, A. The meanings and confusions of weberian 'rationality'. The British Journal of Sociology, London, 29 (1): 57 - 70, mar., 1978.

GAITAN, F. G. Administracion publica. Republica de Colombia: Escuela Superior de Administracion Publica, 1989.

GUERREIRO RAMOS, A. A nova ignorância e o futuro da administração pública na América Latina. Revista da Administração Pública, RAP, Rio de Janeiro, 4 (2): 7-45, 1970.

GUERREIRO RAMOS, A.. A nova ciência das organizações: uma reconceituação da riqueza das nações. 2. ed. Rio de Janeiro: Fundação Getúlio Vargas, 1989.

GUIMARÃES, T. B.; ALMEIDA, B. O duplo planejamento. In: VILHENA, R.; MARTINS, H. F.; MARINI, C.; GUIMARÃES, T. B. O choque de gestão em Minas Gerais: políticas da gestão pública para o desenvolvimento. Belo Horizonte: UFMG, 2006.

GUIMARÃES, T. B.; CAMPOS, E. S. A. Gestão da estratégia no governo do estado de Minas Gerais: em busca da harmonia entre a ação e os resultados. In: XIII Congreso Internacional del Clad sobre la Reforma del Estado y de la Administración Pública, Buenos Aires, Argentina, 4-7 nov. 2008. Anais... Buenos Aires: Consad, 2008. 
Choque de gestão ou choque de racionalidades? O desempenho da administração pública em questão

GUIMARÃES, T. B.; CAMPOS, E. S. A. Programa estado para resultados: balanço da implementação de um escritório de apoio à gestão estratégica e gestão por resultados em Minas Gerais. In: II Congresso Consad de Gestão Pública. Anais... Brasília: Consad, 2009.

HATRY, H. P. Performance measurement: getting results. Washington, DC: Urban Institute Press, 1999.

KALBERG, S.. Max Weber`s types of rationality: cornstones for the analysis of rationalization process in history. American Journal of Sociology, Chicago, 85 (5): 1145 1179, Mar 1980.

LAIA, M. M. Governança eletrônica. In: VILHENA, R.; MARTINS, H. F.; MARINI, C.; GUIMARÃES, T. B. O choque de gestão em Minas Gerais: políticas da gestão pública para o desenvolvimento. Belo Horizonte: Editora UFMG, 2006.

LEMOS, C.S.; NEVES, F.S. A carreira do gestor público em Minas Gerais no contexto do choque de gestão. XIII Congreso Internacional del Clad sobre la Reforma del Estado y de la Administración Pública, Buenos Aires, Argentina, 4 - 7 nov. 2008.

LONDON, Alex J. Threats to the common good: biochemical weapons and human subjects research. The Hastings Center Report, Washington, 33 (5): 17 - 25, sep.-out., 2003.

MANNHEIM, K. O homem e a sociedade: estudos sobre a estrutura social moderna. Rio de Janeiro: Zahar Editores, 1962.

MARCUM, Deanna B. Defining “common good" in digital world. American Philosophical Society, Philadelphia, 145 (1): 73 - 80, March 2001.

MARITAIN, Jacques; FITZGERALD, John J. The person and the common good. The Review of politics, Indiana, 8 (4): 419 - 455, Oct. 1946.

MARTINS, H. Administração para o desenvolvimento: a relevância em busca de disciplina. In: LEVY, E.; DRAGO, P. A. Gestão pública no Brasil contemporâneo. São Paulo: Edições Fundap, 2006, p. 40-56.

MATIAS-PEREIRA, J. Curso de administração pública: foco nas instituições e ações governamentais. 2. Ed. São Paulo: Atlas, 2009. 
MISOCZKY, M. C.. Uma Defesa da Reflexão Teórico Crítica na Pesquisa e Prática da Administração Pública. Anais do I Encontro de Administração Pública e Governança, ANPAD, Rio de Janeiro, 2004.

MOTTA, P. R. Administração para o desenvolvimento - A disciplina em busca de relevância. Revista de Administração Pública, Rio de Janeiro, v. 6, n. 3, p. 39-53, jul./set., 1972.

NEVES, F. S.; MORAIS, M. R.; FURTADO, R. G.; VILAÇA, T. A.. Inovação e compartilhamento de boas práticas na gestão pública: caminhos para o comprometimento dos pares e a valorização das idéias. In: III Congresso Consad de Gestão Pública. Anais... Brasília: Consad, 2010.

NORMAN, F.; Equipe da SEF. O equilíbrio das contas. In: VILHENA, R.; MARTINS, H. F.; MARINI, C.; GUIMARÃES, T. B. O choque de gestão em Minas Gerais: políticas da gestão pública para o desenvolvimento. Belo Horizonte: Editora UFMG, 2006a.

O'CONNOR, J. Making a case for the common good in a global economy. Journal of Religious Ethics, 30 (1): 157 - 173, 2002.

PAULA, A. P. P. Por uma nova gestão pública: limites e potencialidades da experiência contemporânea. Rio de Janeiro: Editora FGV, 2005.

PETERS, B. G.. Government reform and reorganization in a era of retrenchment and conviction politics. In: FARAZMAND, A.. Handbook of comparative and development public administration. New York: Dekker, 1991.

PLANO MINEIRO DE DESENVOLVIMENTO INTEGRADO. Belo Horizonte: Governo do Estado de Minas Gerais, 2003.

RODRIGUES, I. F.; BRASIL, F. P. D. Contribuições e potenciais da governança eletrônica para a democracia: transparência, controle público e participação cidadã - uma análise dos sítios das secretarias de estado de Minas Gerais. In: III Congresso Consad de Gestão Pública. Anais... Brasília: Consad, 2010.

ROUSSEAU, J. J. O contrato social: princípios do direito político. São Paulo: Martins Fontes, 2006. (Original do ano de 1762).

SANDER, B. Gestão da educação na América Latina: construção e reconstrução do conhecimento. Campinas: Autores Associados, 1995. 
Choque de gestão ou choque de racionalidades? O desempenho da administração pública em questão

SILVA, M. P. Bases conceituais e programáticas do choque de gestão na saúde em minas Gerais. In: XI Congreso Internacional del Clad sobre la Reforma del Estado y de la Administración Pública, Salvador de Bahia, 27-30 nov. 2009.

VIEIRA, M. M. F. Por uma (boa) pesquisa qualitativa em administração. In:VIEIRA, M.M.F.; ZOUAIN, D. M.(Orgs.). Pesquisa qualitativa em administração. Rio de Janeiro: FGV, 2006.

VILHENA, R.; ATHAYDE, L. A. Choque de Gestão na administração pública. In: $X$ Congreso Internacional del Clad sobre la Reforma del Estado y de la Administración Pública, Santiago, Chile, 18-21 oct. 2005.Anais... Santiago: Consad, 2005.

VILHENA, R. M. P.; MARINI, C. Os Acordos de Resultados de $2^{\circ}$ etapa: alinhando a SEPLAG com a segunda geração do Choque de Gestão em Minas Gerais. Disponível em: www.consad.org.br, Acesso em: 13 jul. 2010.

VILHENA, R.; MARTINS, H. F.; MARINI, C.; GUIMARÃES, T. B. O choque de gestão em Minas Gerais: políticas da gestão pública para o desenvolvimento. Belo Horizonte: Editora UFMG, 2006.

\footnotetext{
${ }^{1}$ Entende-se por sociedade centrada no mercado a sociedade que tem o mercado como único e principal enclave, tornando-se este influente sobre todas as dimensões da vida humana, desconfigurando-a.

${ }^{2}$ A edição original da obra $O$ contrato social: princípios do direito político é do ano de 1762.
}

\section{AGRADECIMENTO}

Este trabalho é dedicado à memória do Professor Marcelo Milano Falcão Vieira, um dos autores do artigo, que infelizmente nos deixou muito cedo.

Fica aqui um agradecimento especial ao querido Prof. Marcelo, por toda dedicação ao nosso processo de formação pessoal e profissional, que resultou no trabalho que aqui se apresenta.

Lembramos, ainda, que esta é, provavelmente, a última publicação da carreira memorável do autor, em uma revista pela qual tinha tanto apreço. Mas suas contribuições acadêmicas não terminam por aqui, uma vez que a singularidade de seu pensamento ainda há de se perpetuar por muitas gerações de pesquisadores da área. 